\title{
Organic Foulants Characteristics in Membrane Bioreactor
}

\author{
R. K. Aryal ${ }^{1}$, S. Vigneswaran ${ }^{2 *}$, J. Lebegue ${ }^{3}$, H. K. Shon ${ }^{4}$, J. Kandasamy ${ }^{5}$, M. Heran $^{6}$ \& \\ Alain Grasmick ${ }^{7}$ \\ ${ }^{1,2,4 \& 5}$ Faculty of Engineering, University of Technology, Sydney, P.O. Box 123, Broadway, NSW 2007, Australia \\ ${ }^{3,6 \& 7}$ UMR Génie des Procédés Eau et Bioproduits (UMR-CIRAD 016), Université Montpellier II, CC005, Place \\ Eugène Bataillon; 34095, Montpellier Cedex 05, Erance
}

\begin{abstract}
A laboratory scale side stream membrane bioreactor system with flat sheet membrane was operated for 5-days run at three different aeration rates $(100,200$ and $300 \mathrm{~L} / \mathrm{h})$. The organic foulants deposited on the membrane surface was studied after extraction with $5 \% \mathrm{NaOH}$ solution using three spectroscopic techniques. The IR spectra showed no distinct similarity in pealss among the three. The fluorescence spectra showed increase of soluble microbial products in foulant with decrease of aeration rate. This was supported by the size exclusion chromatography in which biopolymers concentration in fouling decreased with increasing aeration rate.
\end{abstract}

Keywords: Aeration rate, foulant, MBR

\subsection{INTRODUCTION}

In recent days, membrane bioreactor (MBR) is the most promising process in water and wastewater treatment due to their potential advantage, such as complete removal of solids from an effluent, superior nutrient and organic removals, high loading rate capabilities, low sludge production and small footprint [1]. However, one of the major hurdles of the membrane filtration system is the fouling on membrane surfaces that decreases the efficiency of the membrane with time. It has been reported that dominating fouling agents causing membrane surface blocking are extra-cellular polymeric substances and soluble microbial byproducts. Besides, the build up of biomass calke layer on the membrane surface (sludge accumulation) also cannot be neglected [2-4].

Controlling fouling in submerged membrane systems remain challenge. Aeration is one of the

\footnotetext{
*Correspondence to: S. Vigneswaran (email: vigid@eng.uts. edu.au)
}

most common strategies by producing flow circulation and shear stress on membrane surface to reduce and control fouling as well as sludge accumulation $[5,6]$. Aeration affects the MBR performance by changing the migration velocity of the particles. Bubbles flowing near to the membrane induce local shear stress and mitigate fouling by constant scouring of the membrane surface [7]. Different degree of aeration produces the local shear stress and favouring hydraulic distribution throughout the fibre network $[8,9]$. However, it is still challenging task for MBR operators to achieve effective aeration to reduce the fouling propensity. Besides, membrane aeration represents an important part of SMBR functioning cost. This work aims to study the change in characteristics the foulant when run at different aeration rate. Three spectroscopic techniques: Fourier-Transformation infrared spectroscopy, fluorescence spectroscopy and high performance size exclusion chromatography were applied for the discussion. 


\subsection{EXPERIMENTAL}

\subsection{Experimental Set-up and Operating Conditions}

\subsubsection{Pilot set-up}

A bioreactor $36 \mathrm{~L}$ in volume, configured into two tanks, one for the flat sheet membrane (also called side stream) and another for aeration was set up in the laboratory (Figure 1). Flat sheet membrane module (PVDF with pore size $0.14 \mu \mathrm{m}$ with filtration area $0.2 \mathrm{~m}^{2}$ ) was submerged in the membrane side stream tank. The mixed liquor was continuously re-circulated between the membrane tank and biological tank with a pump. Larger bubbles (2-4 $\mathrm{mm}$ in diameter) at three different aeration rate $\left(1.0-3.0 \mathrm{~m}^{3} / \mathrm{h} / \mathrm{m}^{2}\right)$ were injected on surface area of membrane $\left(0.2 \mathrm{~m}^{2}\right)$ from the bottom of the membrane tank continuously to produce shear stresses on the membrane surface to minimise sludge accumulation by constant scouring of the membrane surface. Air flow rate injected in the biological aeration tank contained fine bubbles to maximise mixing and oxygen transfer. Membrane filtration was performed in a continuous mode from outside to inside, with no relaxation or back-wash procedure. Permeate was extracted by a perilstic pump at a constant flux. Pressure transducers with on-line data acquisition allowed the monitoring of the trans-membrane pressure (TMP) every 20 minutes.

\subsubsection{Operating Conditions}

The MBR was continuously fed with a synthetic substrate (ethanol, ammonium chloride, potassium dihydrogen phosphate) to keep the ratio COD:N:P equal to $150: 5: 1$ with an organic load of $1.5 \mathrm{~kg}$ COD $\cdot \mathrm{m}^{-3} \cdot \mathrm{d}^{-1}$ with permeate flux of $10 \mathrm{~L} \cdot \mathrm{m}^{2} \cdot \mathrm{h}^{-1}$. TSS concentration was maintained between $4-5 \mathrm{~g} / \mathrm{L}$ with dissolved oxygen greater than $2 \mathrm{mg} / \mathrm{L}$. The MBR was operated over a period of 30 days for seeding the sludge prior to running experiments. Three 5-days runs of different aeration $(100,200$ and $300 \mathrm{~L} / \mathrm{h})$ were performed. The membrane after each run was taken out and washed with water by submerging it into water tank to remove the sludge accumulation in between the membrane. The foulant attached on the membrane surface was then extracted with $\mathrm{NaOH}$ solution $(5 \%$ w/v) using horizontal shaker for $3 \mathrm{hrs}$. The extracted foulant was filtered through $1.2 \mu \mathrm{m}$ filter and diluted to make DOC equivalent to $10 \mathrm{mg} / \mathrm{L}$ for comparative study. Then extracted foulant was analysed. In result and discussion part the foulant refers to the $\mathrm{NaOH}$ extract foulant.

Biological suspension was monitored by COD measurement, soluble microbial products (SMP) after filtering through $1.2 \mu \mathrm{m}$ filter. In SMP proteins was quantified using Lowry method using Bovine Serum Albumin (BSA) as the standard (Sigma) and polysaccharides was quantified by Dubois method using sucrose as standard (UV/Visible spectrometer).
1. Feed tank

2. Bioreactor

3. Filtration cell

4. Membrane module

5. Bioreactor air distributor

6. Membrane air distributor

7. Air compressor

8. Pressure sensor

9. Permeate

10. Recirculating pump

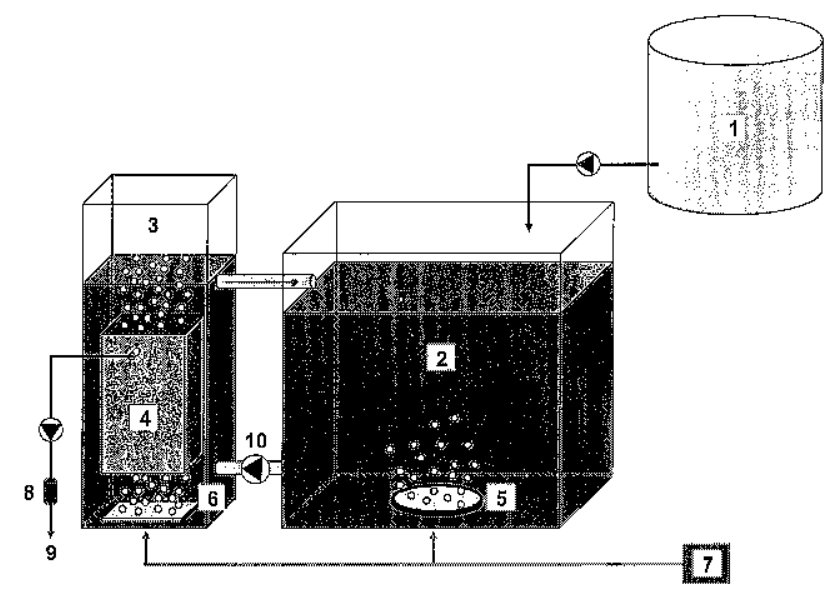

Figure 1 MBR configuration 
Prior to each run the membrane was cleaned with $\mathrm{NaOH}$ solution ( $5 \%$ for $3 \mathrm{hrs}$ ) followed by citric acid $(0.5 \%$ for $12 \mathrm{hrs})$ and sodium hypochloride ( $200 \mathrm{ppm}$ for $3 \mathrm{hrs}$ ) to ensure proper cleaning and membrane hydraulic resistance was measured before running the experiment.

\subsubsection{Foulant Analysis}

\section{(i) Fluorescent Analysis}

Excitation emission matrices (EEMs) were obtained using a spectrofluorometer (Hitachi F4500) with a wavelength range of $200 \mathrm{~nm}$ to $600 \mathrm{~nm}$ by increasing the wavelength by $5 \mathrm{~nm}$ for excitation and emission. Selected fluorescent intensities (excitation:emission) were picked up and compared the abundance of fouling substances when run at different aeration rate.

\section{(ii) FTIR Analysis}

FTIR spectra were collected using $2-5 \mathrm{mg}$ of foulants obtained from freeze drying the extract solution ( $5 \% \mathrm{NaOH}$ ) from Perkin Elmer System 2000. The instrument was setup to scan from 4000 to $600 \mathrm{~cm}^{-1}$. Peak frequency assignment for compound classes were compared with literature $[10,11]$.

(iii) Molecular Weight Distribution Analysis The MWD was measured using high pressure size exclusion chromatography (HPSEC, Shimadzu Corp., Japan) with a SEC column (Protein-pak 125, Waters Milford, USA). MilliQ water with phosphate ( $\mathrm{pH} 6.8)$ and $\mathrm{NaCl}(0.1 \mathrm{M})$ was used as eluent. Eluent flow rate was $1.0 \mathrm{~mL} / \mathrm{min}$. The UV wavelength $254 \mathrm{~nm}$ and fluorescent wavelength (Ex:Em) 250:340 were applied for the detection. Standards of MW of various polystyrene sulfonates (PSS: 210, 1800, 4600, 8000, and $18000 \mathrm{Da}$ ) were used to calibrate the equipment. The details of these experiments are given elsewhere $[12,13]$.

\subsection{Results and Discussion}

Figure 2 shows the measurements of biological parameters (soluble mixed liquor proteins, polysaccharides and COD) during the entire MBR operation period. The COD and SMP showed

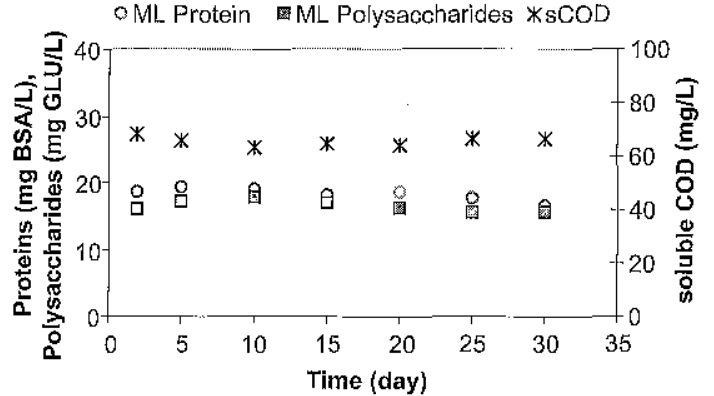

Figure 2 Variation of biological parameters during the experiment period

very stable during the experimental period. It indicated no major changes in wastewater.

Figure 3 (left) shows the IR spectra of foulants run at three aeration rate $(100,200$ and 300 $\mathrm{L} / \mathrm{h}$ ). The spectra did not exactly show similar trend in the run. Run at aeration of 100 and 200 $\mathrm{L} / \mathrm{h}$ showed similarity in $1460 \mathrm{~cm}^{-1}$ where as run at aeration of $200 \mathrm{~L} / \mathrm{h}$ and $300 \mathrm{~L} / \mathrm{h}$ showed similarity in $2360 \mathrm{~cm}^{-1}$ region. Run at $100 \mathrm{~L} / \mathrm{h}$ showed good spectral band in $3000-3500 \mathrm{~cm}^{-1}$ region where as in the same region the run at 200 $\mathrm{L} / \mathrm{h}$ and $300 \mathrm{~L} / \mathrm{h}$ showed weak and wide band. The difference in IR spectra among the foulant may explain the difference in adsorption phenomenon of foulant on the membrane surface when run at different aeration rate.

The FTIR spectra showed strong band in the region of $795 \mathrm{~cm}^{-1}$ at aeration of $100 \mathrm{~L} / \mathrm{h}$ run indicated presence of aromatic hydrocarbons. The presence of aromatic hydrocarbons indicated their formation on the membrane surface is possibly caused by microbial activity on the membrane surface. Similarly small peak observed in the region $1140 \mathrm{~cm}^{-1}$ indicated fulvic acid substances. Small weak peak in $1650-1580 \mathrm{~cm}^{-1}$ (aromatic hydrocarbons and proteins) and $3500-3300 \mathrm{~cm}^{-1}$ (polysachharides) in all runs indicated presence of aromatic and aliphatic amino groups (proteins and building blocks). This finding suggests that the bio-film that developed on the membrane surface was possibly due to the accumulation of extra-cellular polymeric substances as well as sludging on the membrane surface $[10,11]$. 

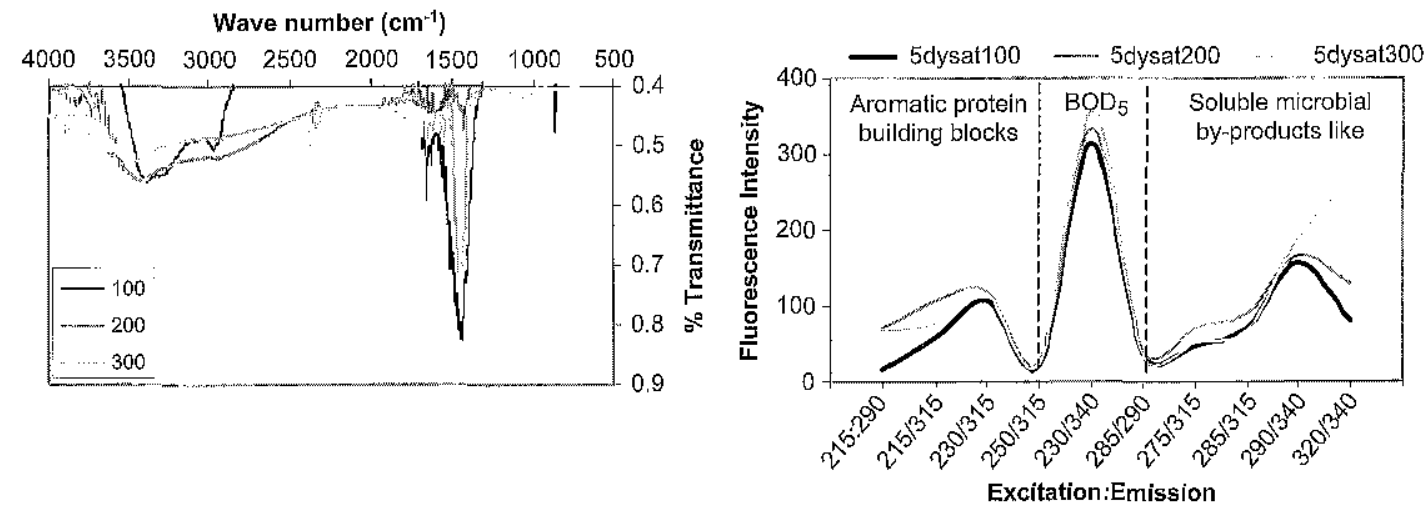

Figure 3 FT-IR spectra (left) and fluorescent spectra (right) of foulant run at three different aeration rate $(100,200$ and $300 \mathrm{~L} / \mathrm{h})$

Fluorescent fingerprint has been widely used to identify the nature of organic substances in water and wastewater [14]. The outstanding advantage of fluorescence spectroscopy is that information regarding the fluorescence characteristics can be entirely acquired by changing excitation wavelength and emission wavelength simultaneously without destructing the samples. Foulant contains wide range of soluble microbial substances and humic substances, results from the spectra would be precious for studying the chemical properties of foulant of various origins [15].

Figure 3 (right) shows the fluorescence intensity obtained from the foulant extract at different excitation emission wavelength. Based on literature [15], the excitation emission was divided into three regions (i) aromatic protein building blocks, (ii) BOD5 substance and (iii) soluble microbial by-products. The fluorescence spectral analysis showed concentration of BOD5 and soluble microbial products decreased with increasing aeration rate. Increase aeration decrease fouling propensity, which may have decreased BOD5 substances and the soluble microbial by-products as well. However, the trend could not be seen in aromatic protein building block region.

Figure 4 shows chromatograms of foulant extract obtained from 5-days runs for three aeration rate $(100,200$ and $300 \mathrm{~L} / \mathrm{h})$ obtained by size exclusion chromatography using UV (254 $\mathrm{nm}$ ) and fluorescence (Ex:Em 250:340) detectors. Chemical components appeared as a peak at different times were named according to their retention time $[13,16]$ after comparing with the standard sample solution. Table 1 shows the specific components in terms of different MWs.

The four main peak families, biopolymers (35 kDa), humic acids ( $1 \mathrm{kDa})$, building blocks $(780 \mathrm{Da})$ and low molecular weight acids (250 $\mathrm{Da})$ were detected. HPSEC chromatograms of foulant attached on the membrane surface for different aeration rate were very similar in shape

Table 1 MW for each substance and retention time in size exclusion chromatography

\begin{tabular}{llcc}
\hline & Substance & MW (Da) & Retention time (in this work) (min) \\
\hline BP & Biopolymers & 35,000 & 6.54 \\
HA & Humic acids & 1,000 & 11.02 \\
BB & Building block & 750 & 11.38 \\
AC & Low MW acids & 250 & 12.50 \\
AM & Amphiphilics & $<200$ & 13.7 \\
\hline
\end{tabular}



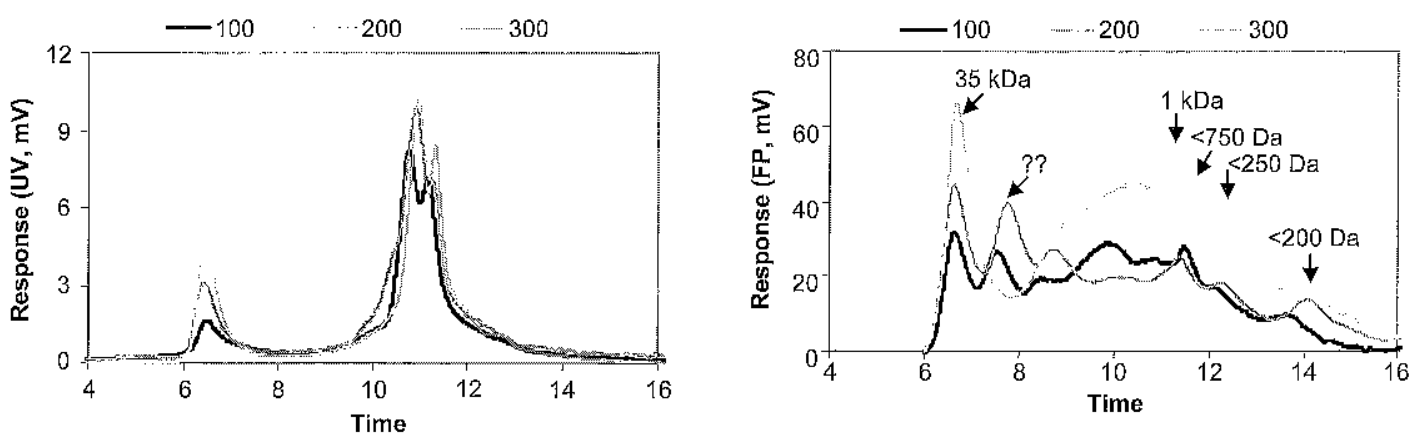

Figure 4 UV (left) and fluorescence (right) response of foulants relating to molecular weight distribution

for UV response exhibiting four different peaks at $6.54,11.02,11.38$, and 12.86 min corresponded to $35 \mathrm{kDa}, 1 \mathrm{kDa}, 750 \mathrm{Da}$, and $<200 \mathrm{Da}$. Biopolymers include polysaccharides and proteins, building blocks are considered as hydrolysates of humic substances, mono and diprotic low-molar-mass organic acids (including amnio acids), low amphiphilics (slightly hydrophobic) compounds include sugars, alcohols, aldehydes, ketones [16, 17]. The peak observed for 11.03 and 11.38 overlapped, which we believed due to higher eluent flow rate $(1 \mathrm{~mL} /$ min). The last peak with weak intensity had broader low molecular weight substances.

Figure 4 shows the UV response chormatogram (left) and the fluorescence response chromatogram (right) obtained from high pressure size exclusion chromatography. The UV response in molecular weight distribution analysis showed similar chromatogram pattern in each run for large molecular weight substances ( $35 \mathrm{kDa}$ ) but variation in concentration. It is seen that in both UV and fluorescence spectra the biopolymer peaks decreased with increasing aeration rate. This shows that higher aeration rate decrease the fouling propensity by affecting the foulant formation mechanism. Humic acid type substances responded well in UV spectra but correlation with aeration rate could not be made which is possibly due to complex humic substances in the foulant. The fluorescence response (Figure 4 (right)) also showed similar chromatogram patterns for large molecular weight substances (biopolymers like) with different concentrations but for lower molecular weight substances the peak patterns (chromatogram) were quite different from one another indicating large variation in nature of organic substances in foulant. Large difference in spectra for low molecular weight substances such as humic acid (1 $\mathrm{kDa})$, building blocks such as hydrolysate of humic substances, mono- and diprotic acids (750 Da) and low ampiphilic compounds $(<200 \mathrm{Da})$ indicated variation in enrichment of low molecular weight substances in each run by nature as well as by concentration.

\subsection{CONCLUSION}

Membrane bioreactor was run at three different aeration rates $(100,200$ and $300 \mathrm{~L} / \mathrm{h})$ for 5 -days in each. A similar range of biopolymer (protein) in the mixed liquor during the experiment was observed. The organic foulants deposited on the membrane surface showed strong influence of aeration in fouling propensity. The FTIR spectra showed no major similarity in all three runs that indicated wide range of functional groups in foulants. The fluorescence spectral comparison at different excitation emission region indicated higher rate of production of soluble microbial byproducts on the membrane surface which could be reduced by increasing the membrane aeration rate. Higher degree of biopolymeric substances found on the membrane surface indicated production of biopolymers on the membrane surface possibly due to chemical conversion of attached materials with time. The size exclusion chromatography also showed higher production 
of biopolymeric substances at lower aeration rate.

The turbulence created by aeration is a critical factor affecting foulant deposition on the membrane surface. Further study is recommended to determine the bubble numbers and sizes at different aeration rates.

\section{REFERENCE}

[1] Engelhardt, N., W. Firk, and W. Warnken. 1998. Integration of Membrane Filtration into the Activated Sludge Process in the Municipal Wastewater Treatment. Water Science and Technology. 38: 429-436.

[2] Metzger, U., P. Le-Clech, R.M. Stuetz, F.H. Frimmel, and V. Chen. 2007. Characterisation of Polymeric Fouling in Membrane Bioreactors and the Effect of Different Filtration Modes. Journal of Membrane Science. 301 (2007): 180-189

[3] Lebegau, J., M. Heran, and A. Grasmick. 2007. Membrane Air Flow Rates and HF Sludging Phenomenon in SMBR. Proceed ings of the Sixth International Membrane Science and Technology Conference, November 5-9, Sydney, Australia.

[4] Judd, S. 2006. The MBR Book: Principles and Applications of Membrane Bioreactors for Water and Wastewater Treatment. Elsevier Science: Netherlands.

[5] Bouhabila, E.H., R. Ben Aïm, and H. Buisson. 2001. Fouling Characterisation in Membrane Bioreactors. Separation and Purification Technology, 22-23: 123-132.

[6] Liu, R., X. Hunag, Y. Feng Sun, and Y. Qian. 2003. Hydrodynamic Effect on Sludge Accumulation over Membrane Surfaces in a Submerged Membrane Bioreactor. Process Biochemistry. 39: 157-163.

[7] Dufresne, R., R.E. Lebrun, and H.C. Lavalle. 1997. Comparative Study on Fluxes and Performances during Papermill Wastewater Treatment with Membrane Bioreactor. Canadian Journal of Chemical Engineering. 75: 95-103.

[8] Sofia, A., W. Ng, and S.L. Ong. 2004. Engineering Design Approaches for
Minimum Fouling in Submerged MBR. Desalination. 160(1): 67-74.

[9] Meng, F., F. Yang, B. Shi, and H. Zhang. 2008. A Comprehensive Study on Membrane Fouling in Submerged Membrane Bioreactors Operated under Different Aeration Intensities. Separation and Purification Technology. 59: 91-100.

[10] Jarusutthirak, C., and G. Amy. 2001. Membrane Filtration of Wastewater Effluents for Reuse: Effluent Organic Matter Rejection and Fouling. Water Science and Technology, 43 (10): 225-232.

[11] Chefetz, B., T. Ilani, E. Schult, and J. Chorover. 2006. Wastewater Dissoloved Organic Matter: Characteristics and Sorptive Capabilities. Water Science and Technology. 53(7): 51-57.

[12] Her, N.G. 2002. Identification and Characterization of Foulants and Scalants on NF Membrane. Ph.D. Thesis of Philosophy. University of Colorado. pp 4049.

[13] Huber, S.A. 1998. Evidence for Membrane Fouling by Specific TOC Constituents. Desalination. 119: 229-234.

[14] Sheng, G.P., and H.Q. Yu. 2006. Characterisation of Extracellular Polymeric Substances of Aerobic and Anaerobic Sludge using Three-dimensional Excitation and Emission Spectroscopy. Water Research. 40: 1233-1239.

[15] Chen, W., P. Westerhoff, J. Leenheer, and K. Booksh. 2003. Fluorescence ExcitationEmission Matrix Regional Integration to Quantify Spectra for Dissolvoed Organic Matter. Enviornmental Science and Technology. 37: 5701-5710.

[16] Rosenberg, S., and M. Kraume. 2002. Filterability of Activated Sludge in Membrane Bioreactors. Desalination. 146(1-3): 373-379.

[17] Shon, H.K., S. Vigneswaran, S. Kim, J. Cho, and H.H. Ngo, 2006. Fouling of Ultrafiltration Membrane by Effluent Organic Matter: A Detailed Characterization using Different Organic Fractions in Wastewater. Journal of Membrane. Science. 278: 232238. 